\title{
Terminal Deletion of the Long Arm of Chromosome 2 in a Mildly Dysmorphic Hypotonic Infant With Karyotype 46,XY,del(2)(q37)
}

\author{
Jerome L. Gorski, Beth A. Cox, Mi Kyine, Wendy Uhlmann, and Thomas W. Glover \\ Division of Pediatric Genetics (J.L.G., B.A.C., M.K., T.W.G.), Department of Pediatrics (J.L.G., T.W.G.), and Department \\ of Human Genetics (J.L.G., W.U., T.W.G.), University of Michigan Medical Center, Ann Arbor
}

\begin{abstract}
We describe a boy with severe hypotonia and minor facial anomalies with a terminal deletion of chromosome $2 q(46, X Y, \operatorname{del}(2)(q 37))$. Comparison with previous cases in the literature indicates that this particular deletion results in infantile hypotonia, developmental delay, and minor craniofacial anomalies including frontal bossing and micrognathia. The absence of true malformations and few minor anomalies in this patient suggests that indications for obtaining a chromosome analysis from neurologically impaired individuals need to be reevaluated.
\end{abstract}

KEY WORDS: chromosome aberration, aneuploidy, malformation syndrome, mental retardation

\section{INTRODUCTION}

Deletions of chromosome 2 are rare and are usually observed as part of more complex duplication-deletion syndromes among progeny of balanced reciprocal translocation carriers [Schinzel, 1984]. We present a previously unrecognized de novo terminal deletion of $2 q 37$ in a patient with severe hypotonia, developmental delay, and minor facial anomalies.

\section{CLINICAL REPORT}

J.G. was the first child of healthy parents. He was the $3,350 \mathrm{-g}$ product of a term gestation to a 30 -year-old primigravida. The first trimester was complicated by a fever without localizing signs and a vaginal fungal infec-

Received for publication May 2, 1988; revision received October $10,1988$.

Address reprint requests to Dr. Jerome L. Gorski, Division of Pediatric Genetics, Department of Pediatrics, D1109 MPB, Box 0718, University of Michigan, Ann Arbor, MI 48109. tion which were treated with oral antibiotics and topical ointments. His mother denied the use of other drugs or alcohol. Family history was unremarkable with regard to consanguinity, miscarriages, congenital anomalies, or mental retardation. An uncomplicated spontaneous vaginal delivery was performed at 40 weeks. Apgar scores were 9 and 10 at 1 and $5 \mathrm{~min}$.

Developmental delay was apparent at age 6 months. At 15 months he was observed to be severely hypotonic and without head control with his development limited to fixing, following a full $180^{\circ}$, and smiling occasionally. $\mathrm{He}$ began to roll over and to reach for objects at 18 months. At 21 months he intermittently pulled to stand, had a two-word vocabulary, and began to play pattycake. At 32 months evaluations by Rockford Infant Developmental Evaluation Scales and Erhardt Developmental Prehension Assessment found him to be functioning at a 6- to 12 -month level. He has been without other significant medical problems.

At 21 months he was severely hypotonic and lay in a frog-like position when supine. Muscle strength and deep tendon reflexes were normal. No contractures, focal neurological abnormalities, or abnormal reflexes were present. Examination at 33 months showed a boy with an occipitofrontal circumference (OFC) of $49.5 \mathrm{~cm}$ (25 centile), height of $95.5 \mathrm{~cm}$ (50 centile), and weight of $14.1 \mathrm{~kg}$ (50 centile). Facial anomalies were limited to slight frontal bossing, deeply set eyes, highly arched palate, mild micrognathia, malar prominence, and long eyelashes (Fig. 1). No cardiac murmurs have been perceived upon repeated auscultations. Inverted nipples were present bilaterally. His hands had proximally placed triradii, normal palmar and digital creases without apparent dermatoglyphic abnormalities. Eczematoid lesions were present on his hands and cheeks. He had an unsteady rigid gait, but no focal neurological abnormalities were apparent. He exhibited self-stimulatory teeth grinding and ritualistic hand waving behavior. Repeated ophthalmologic examinations and audiologic evaluations have been normal.

Laboratory investigations have included a normal creatine phosphokinase (CPK), normal paper chromatographic screen for urine amino and organic acids, and

(C) 1989 Alan R. Liss, Inc. 


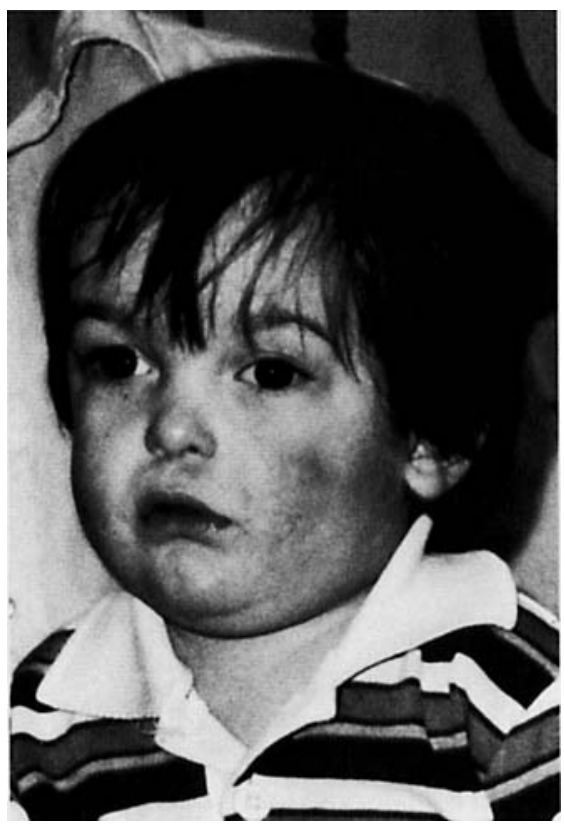

Fig. 1. The patient at 21 months.

normal quantitations of leukocyte lysosomal enzymes. Parental consent has been withheld for skeletal survey, cranial computerized tomography (CT) scan, electromyography, and nerve conduction velocity studies.

\section{CYTOGENETIC STUDIES}

The chromosomes of 20 cells were analyzed. The modal chromosome number was 46 . Prometaphase trypsinGiemsa and $\mathrm{R}$ banding studies of peripheral lymphocytes and Epstein Barr virus (EBV)-transformed lymphoblasts showed a terminal deletion of band q37 of chromosome 2 (Fig. 2): karyotype 46,XY,del(2)(pter $\rightarrow$ q37::). Parental chromosomes were normal.

\section{DISCUSSION}

We present a heretofore unrecognized syndrome consisting of severe developmental delay, nonprogressive hypotonia, and minor facial anomalies associated with an apparently terminal deletion of band $2 q 37$. The pathophysiologic basis for the patient's hypotonia remains unclear, but is clinically consistent with a central nervous system abnormality.

We are aware of only two other reports of patients with uncomplicated deletions involving 2q37 [Sánchez and Pantano, 1984; Young et al., 1983]. Clinical traits common to two or more of the patients with terminal $2 q$ deletions, with the most proximal breakpoint to the left, are summarized in Table I. It is apparent that while there is a degree of clinical heterogeneity among the described patients, the two previously described cases, which share an apparent monosomy for $2 \mathrm{q} 36$ to $2 \mathrm{q}$ terminus, are concordant for many clinical manifestations including intrauterine growth retardation, developmental delay, microcephaly, a cleft or highly arched palate, abnormally

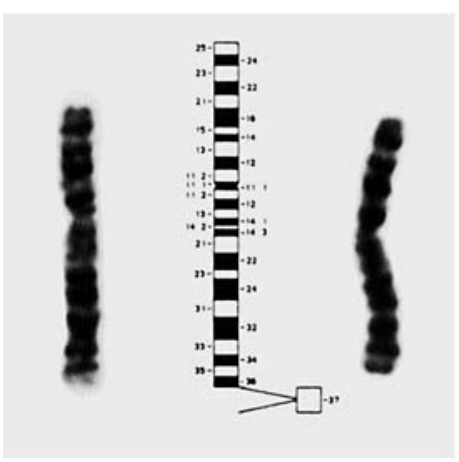

Fig. 2. Partial karyotype of the patient showing, to the left, the patient's Giemsa-banded normal chromosome 2; to the right, the patient's Giemsa-banded deleted chromosome 2q37; and in the middle, a schematic diagram of chromosome 2 illustrating the patient's deletion.

slanted palpebral fissures, apparently low set ears, and syndactyly. The patient of Sánchez and Pantano [1984], monosomic for $2 \mathrm{q} 35$ to $2 \mathrm{q}$ terminus, had additional clinical manifestations consisting of micrognathia, strabismus, a thin nose with hypoplastic nasal alae, a long philtrum, macrostomia, thin lips, hypoplastic teeth, short neck, simian creases, and ulnarly deviated digits. The patient of Young et al. [1983] had the unique clinical manifestations of bilateral epicanthic folds, a flat nasal bridge, absent uvula, inverted nipples, arachnodactyly, spina bifida occulta of $\mathrm{T} 1$ to $\mathrm{T} 8$, and seizures.

The physical abnormalities of our patient were primarily limited to a subset of the common traits of the three compared patients and consisted of developmental delay, hypotonia, long eyelashes, a highly arched palate, and micrognathia. The present patient was discordant, specifically, in not being growth retarded at birth, or microcephalic, or having limb anomalies, or abnormal palpebral fissure, or ear anomalies. Compared to the other two reported terminal (del) $(2 q)$ cases, our patient's unique facial anomalies were limited to deep set eyes and mild frontal bossing.

The origin of the discordant phenotype of the compared patients is unclear and could have several possible nonexcluding explanations. Unrecognized complications in the chromosome analysis or interpretations, a concern raised by Young et al. [1983], is a possibility. In addition, variability in phenotypic expression may account for some or all of the discordant clinical manifestations among multiple patients sharing a common chromosome abnormality. Alternatively, it is possible that the various loci that influence development present on $2 q$ terminus do not necessarily act in a strictly additive fashion. The clinical heterogeneity among the compared patients is consistent with the existence of multiple genes, each capable of influencing developmental processes, being distributed on chromosome $2 q$ between $2 q 35$ and $2 q$ terminus, together acting in a complex additive and nonadditive fashion, with various patterns of loss of loci resulting in partially concordant and discordant phenotypes. At this point, no definitive $2 \mathrm{q}$ terminus-deletion 
TABLE I. Clinical Traits Common to Two or More Patients With 2q Terminal Deletions

\begin{tabular}{lccc} 
& $\begin{array}{c}\text { Sanchez and } \\
\text { Pantano [1984] }\end{array}$ & Young et al. & $\begin{array}{c}\text { Out } \\
\text { patient }\end{array}$ \\
\hline Deleted segment & [1983] & q36 $\rightarrow$ qter & q37-r $\rightarrow$ qter \\
Birth weight at term $(\mathrm{g})$ & 2100 & 2300 & 3350 \\
Psychomotor retardation & + & + & + \\
Microcephaly & + & + & - \\
Hypotonia & + & + & + \\
Long eyelashes & + & + & + \\
Cleft or highly arched palate & + & + & + \\
Micrognathia & + & + & - \\
Antimongoloid palpebral fissures & + & + & + \\
Apparently low set ears & - & + & - \\
Inverted nipples & + & & + \\
Syndactyly & & & +
\end{tabular}

syndrome can be delineated. Additional patients may provide sufficient data to successfully address such questions.

Of note are the few facial anomalies in our patient. Band $2 q 37$ represents approximately $5 \%$ of chromosome 2 or $0.4 \%$ of the haploid human genome [Harden and Klinger, 1985] or an estimated 200 genes [Schmickel, 1986], yet the clinically significant abnormalities of the present patient are apparently limited to his central system with few minor facial anomalies. Clinically normal individuals have been reported with small deletions of late replicating Giemsa-dark bands 13q21 [Couturier et al., 1985] and 5p14 [Overhauser et al., 1986]. Generally, individuals with an unbalanced autosomal chromosome constitution have an abnormal phenotype and varying degrees of mental deficiency [Epstein, 1986]. However, observations have modified this generality by recognizing that the severity of the phenotype is dependent, in part, on the characteristics of the chromosome region lacking or in excess. Imbalances involving Giemsa-light bands usually have more severe phenotypic consequences than those involving Giemsa-dark bands [Aurias et al., 1978; Korenberg et al., 1978]. It has been speculated that these differences may relate to an unequal distribution of transcribed DNA between the generally early replicating Giemsa-light bands and the late replicating Giemsa-dark bands [Yunis et al., 1977; Korenberg et al., 1978]. While there is no evidence for a difference in transcriptional activity between early replicating Giemsa-light bands and late replicating Giemsa-dark bands, early replicating DNA contains a much higher proportion of transcribed genes than late replicating DNA [Holmquist et al., 1982; Goldman et al., 1984]. Band 2q37 is an early replicating Giemsa-light band [Dutrillaux et al., 1976], and monosomy for this band could be expected to produce major developmental abnormalities. At this point we do not have an explanation for the apparent incongruity of the expected relatively severe phenotype and the observed mild facial anomalies.

The mildness of the facial anomalies and the apparent lack of major malformations suggest that mental deficiency or central nervous system abnormalities may be the sole manifestation of autosomal aneuploidy. The findings presented in this report support less stringent criteria for obtaining chromosome analysis on mentally impaired individuals independent of the presence of a specific number of major or minor anomalies.

\section{ACKNOWLEDGMENTS}

We gratefully appreciate the assistance of Joanne Owens in the preparation of this manuscript. J.L.G. is supported by National Institutes of Health Physician Scientist Award K11-HD00788.

\section{REFERENCES}

Aurias A, Prieur M, Dutrillaux B, Lejeune J (1978): Systematic analysis of 95 reciprocal translocations of autosomes. Hum Genet 45:259 282.

Couturier J, Morichon-Delvallez N, Dutrillaux B (1985): Deletion of band $13 \mathrm{q} 21$ is compatible with normal phenotype. Hum Genet 70:8791

Dutrillaux B, Couturier J, Richer C-L, Veigas-Péquignot C (1976): Sequence of DNA replication in $277 \mathrm{R}$ and $\mathrm{Q}$ bands of human chromosomes using a BrdU treatment. Chromosoma 58:51-61.

Epstein C.J (1986): "The Consequences of Chromosome Imbalance: Principles, Mechanisms, and Models." Cambridge: Cambridge University Press, pp 22-65.

Goldman MA, Holmquist GP, Gray MC, Caston LA, Nag A (1984): Replication timing of genes and middle repetitive sequences. Science 224:686-692

Harden DG, Klinger HP (eds) (1985): "An International System for Human Cytogenetic Nomenclature.” Basel: S. Karger, p 114.

Holmquist G, Gray M, Porter T, Jordan J (1982): Characterization of Giemsa dark-and-light band DNA. Cell 31:121-129.

Korenberg JR, Therman E, Denniston C (1978): Host spots and functional organization of human chromosomes. Hum Genet 43:13-22.

Overhauser J, Golbus MS, Schonberg SA. Wasmuth JJ (1986): Molec ular analysis of an unbalanced deletion of the short arm of chromosome 5 that produces no phenotype. Am J Hum Genet 39:1-10.

Sánchez JM, Pantano M (1984): A case of deletion 2q35 $\rightarrow$ qter and a peculiar phenotype. J Med Genet 21:147-149.

Schinzel A (1984): "Catalogue of Unbalanced Chromosome Aberrations in Man." Berlin: Walter de Gruyter, pp 101-118.

Schmickel RD (1986): Contiguous gene syndromes: A component of recognizable syndrome. J Pediatr 109:231-241.

Young RS, Shapiro SD, Hansen KL, Hine LK, Rainosek DE, Guerra FA (1983): Deletion 2q: Two new cases with karyotype 46,XY,del(2)(q13(q31q33) and 46,XX,del(2)(q36). J Med Genet 20:199-202.

Yunis JJ, Kuo HT, Saunders GF (1977): Localization of sequences specifying messenger RNA to light-staining G-bands of human chromosomes. Chromosoma 61:335-344. 